\title{
Electroörganic Preparations
}

\author{
IX *. Polarography and Reduction of Substituted Aryl Alkyl Ketones
}

\author{
HEN N I G LUND
}

Leo Pharmaceutical Products, Ballerup, Denmark**

\begin{abstract}
Ketones with the general formula $\mathrm{Ar}-\mathrm{CO}-\mathrm{CRR} \mathrm{X}$, where $\mathrm{R}$ and $\mathrm{R}^{\prime}$ are hydrogen, alkyl or aryl and $\mathrm{X}$ is $-\mathrm{Cl},-\mathrm{OH},-\mathrm{OCH}_{3},-\mathrm{OC}_{6} \mathrm{H}_{6}$, - OOCR, $-\mathrm{SC}_{8} \mathrm{H}_{5},-\mathrm{SCN},-\mathrm{CN}$, or $-\mathrm{ONO}_{2}$, have been investigated polarographically and by means of controlled potential reductions at a macro mercury cathode. In most cases the reduction of the $\mathrm{C}-\mathrm{X}$ bond occurs at less negative potentials than that of the carbonyl group.
\end{abstract}

Some types of 2 -substituted acetophenones have previously been investigaSted polarographically. Thus Pasternak and Halban ${ }^{1}$ studied 2-bromoacetophenone, Adkins and $\operatorname{Cox}^{2} 2$-bromoisobutyrophenone, Elving and Leone ${ }^{3}$ 2-fluoroacetophenone, and Zuman and Horak 4 investigated a series of $\mathrm{N}$ substituted 2-aminoacetophenones. Methylbenzoylcarbinol has been studied by Fedoronko ${ }^{5}$ and benzoin by Pasternak ${ }^{6}$ and Santavy ${ }^{7}$.

Elving and Leone ${ }^{3}$ studied the electrode reaction by means of controlled potential reductions at a macro mercury electrode and Zuman and Horak ${ }^{4}$ identified the reduction products from a prolonged electrolysis at the dropping mercury electrode by means of paper chromatography. In both cases the electrode reaction corresponding to the first wave was a reduction to acetophenone.

Benzoin has been investigated by means of controlled potential reductions by Pasternak ${ }^{6}$, and it was found that the reduction product at $\mathrm{pH} 8$ was hydrobenzoin, whereas the isolated product from a reduction at $\mathrm{pH} 1.3$ was the higher melting form of deoxybenzoin pinacol, 1,2-diphenyl-1,2-dibenzylethylene glycol.

In the present investigation compounds with the general formula $\mathrm{Ar}-$ $\mathrm{CO}-\mathrm{CRR}^{\prime}-\mathrm{X}$, where $\mathrm{R}$ and $\mathrm{R}^{\prime}$ are hydrogen, alkyl or aryl, $\mathrm{X}$ is $-\mathrm{OH}$, $-\mathrm{OCH}_{3},-\mathrm{OC}_{6} \mathrm{H}_{5},-\mathrm{OOCR},-\mathrm{SC}_{6} \mathrm{H}_{5},-\mathrm{SCN},-\mathrm{ONO}_{2}$, or $-\mathrm{CN}$, have been

* Part VIII: Collection Czechoslov. Chem. Communs. In press.

** Present address: Chemical Department, University of Aarhus, Denmark

Acta Chem. Scand. 14 (1960) No. 9 
investigated polarographically and the electrode reactions have been studied by means of controlled potential reductions at a macro mercury electrode. The results obtained at the micro and the macro electrodes are compared and discussed.

\section{RESULTS}

In Table 1 are given polarographic data for 2-hydroxyacetophenone (I), 2-acetoxyacetophenone (II), 2-benzoxyacetophenone (III), 2-phenoxyacetophenone (IV), phenacyl phenyl sulfide (V), 2-thiocyanatoacetophenone (VI), and phenacyl nitrate (VII).

2-Hydroxyacetophenone shows in mineral acid solution two waves. The height of the first wave corresponds to a two-electron reduction, whereas the second one is somewhat smaller than corresponding to a one-electron reduction. The half-wave potential of the second wave coincides with that of acetophenone in the same solution. This suggests that the electrode reaction corresponding to the first wave is a reduction of the primary alcohol to a methyl group and the second wave is due to the reduction of the acetophenone thus formed, and this has been confirmed by a controlled potential reduction. The electrode reaction is analogous to that of certain 16-hydroxy-17-ketosteroids ${ }^{8}$, in which the hydroxyl group is reduced at less negative potentials than the carbonyl group; the half-wave potentials of the steroids are, however, considerably more negative.

At higher $\mathrm{pH}$-values the waves of 2 -hydroxyacetophenone merge; the reduction path is not clear and the low stability of the compound at high $\mathrm{pH}$ -

Table 1. Limiting currents in $\mu \mathrm{A}$ and half-wave potentials $v s$ S.C.E. of 2-hydroxyacetophenone (I), 2-acetoxyacetophenone (II), 2-benzoxyacetophenone (III), 2-phenoxyacetophenone (IV), phenyl phenacyl sulfide (V), 2-thiocyanatoacetophenone (VI), and phenacyl nitrate (VII). Concentration $10^{-3}$ M. $0.008 \%$ gelatin added as maximum suppressor.

\begin{tabular}{|c|c|c|c|c|c|c|c|c|c|c|c|c|}
\hline \multirow{2}{*}{$\begin{array}{c}\mathrm{pH} \\
\text { Com- } \\
\text { pound }\end{array}$} & \multicolumn{2}{|c|}{1.0} & \multicolumn{2}{|c|}{3.5} & \multicolumn{2}{|c|}{5.3} & \multicolumn{2}{|c|}{7.3} & \multicolumn{2}{|c|}{9.7} & \multicolumn{2}{|c|}{13} \\
\hline & $i_{l}$ & $-E_{\frac{1}{2}}$ & $i_{l}$ & $-E_{\frac{1}{2}}$ & $i_{l}$ & $-E_{\frac{1}{2}}$ & $i_{l}$ & $-E_{\frac{1}{2}}$ & $i_{l}$ & $-E_{\frac{1}{2}}$ & $i_{l}$ & $-E_{\frac{1}{2}}$ \\
\hline \multirow[t]{2}{*}{ I } & 4.8 & 0.85 & 4.8 & 1.10 & 5.5 & 1.28 & 6.1 & 1.41 & 6.1 & 1.49 & 4.4 & 1.59 \\
\hline & 1.7 & 1.05 & 1.0 & 1.26 & & & & & & & & \\
\hline \multirow[t]{2}{*}{ II } & 4.9 & 0.75 & 4.6 & 1.00 & 4.7 & 1.15 & 4.9 & 1.30 & 4.5 & 1.32 & 8 & \\
\hline & 2.5 & 1.04 & 0.8 & 1.22 & 0.3 & 1.35 & 3.6 & 1.54 & 4.3 & 1.57 & & \\
\hline \multirow[t]{2}{*}{ III } & 4.3 & 0.75 & 4.4 & 0.93 & 4.4 & 1.13 & 4.1 & 1.27 & 4.3 & 1.32 & $a$ & . \\
\hline & 1.9 & 1.09 & 1.3 & 1.27 & 1.0 & 1.38 & 3.4 & 1.57 & 4.3 & 1.62 & & \\
\hline \multirow[t]{2}{*}{ IV } & 4.5 & 0.83 & 4.5 & 0.96 & 4.3 & 1.09 & 4.3 & 1.22 & 4.2 & 1.32 & 3.2 & 1.41 \\
\hline & 2.3 & 1.09 & 0.8 & 1.26 & 0.5 & 1.4 & 3.1 & 1.55 & 4.1 & 1.62 & $1.8 \mathrm{~b}$ & 1.73 \\
\hline \multirow[t]{2}{*}{ V } & 4.5 & 0.59 & 4.3 & 0.82 & 4.2 & 1.00 & 4.0 & 1.22 & 3.7 & 1.30 & 4.2 & 1.33 \\
\hline & 2.1 & 1.07 & 1.0 & 1.26 & 0.8 & 1.4 & 4.0 & 1.58 & 4.0 & 1.63 & $1.7 \mathrm{~b}$ & 1.73 \\
\hline \multirow[t]{2}{*}{ VI } & 5.1 & 0.51 & 5.2 & 0.66 & 4.9 & 0.68 & 4.6 & 0.68 & 4.6 & 0.67 & $\mathbf{a}$ & \\
\hline & 2.5 & 1.05 & 1.2 & 1.22 & 0.7 & 1.35 & 3.5 & 1.56 & 3.3 & 1.59 & & \\
\hline \multirow[t]{3}{*}{ VII } & 5.5 & 0.45 & 5.0 & 0.46 & 4.6 & 0.46 & a & 0.46 & - & & - & \\
\hline & 10.6 & 0.91 & 14.5 & 1.2 & c & 1.3 & & & & & & \\
\hline & 9.1 & 1.05 & & & & & & & & & & \\
\hline
\end{tabular}

a. The compound is hydrolyzed;

c. Poorly defined wave. b. Minimum between the two waves; 
values makes the results from the preparative reductions dubious. The results seem to indicate that more than two electrons are involved in the reaction and from a partially reduced reaction mixture a minor amount $(10 \%)$ of acetophenone was isolated as the 2,4-dinitrophenylhydrazone.

As in the reduction of tropyl alcohol ${ }^{9}$ the first wave in acid solution of 2-hydroxyacetophenone corresponds to the reduction of the protonated compound, but whether the reaction is a direct reduction of the carbon-oxygen bond or the reduction is preceded by formation of a "phenacylium ion" by loss of water from the protonated compound is not known.

The acetylated compound, 2 -acetoxyacetophenone, shows both in acid and alkaline solution two polarographic waves and the more negative wave occurs at the same potential as that of acetophenone in the same solution. The polarographic data thus suggest that the electrode reaction corresponding to the first wave is a reduction of the acetoxyacetophenone to acetophenone according to

$$
\mathrm{C}_{6} \mathrm{H}_{5} \mathrm{COCH}_{2} \mathrm{OCOCH}_{3}+2 e^{-}+2 \mathrm{H}^{+} \rightarrow \mathrm{C}_{6} \mathrm{H}_{5} \mathrm{COCH}_{3}+\mathrm{CH}_{3} \mathrm{COOH}
$$

and this was confirmed by a controlled potential reduction in acid solution from which acetophenone was isolated in good yield as its 2,4-dinitrophenylhydrazone.

In alkaline solution both waves correspond to two-electron reductions, but no preparative reduction has been made due to the hydrolysis of the compound at high $\mathrm{pH}$-values. The polarographic data, however, strongly suggest a"reduction to acetophenone in this case too. The reduction of 2-acetoxyacetophenone thus resembles that of the acetyl derivatives of the above mentioned steroids ${ }^{8}$.

The polarographic reduction of phenacyl phenyl ether and phenacyl phenyl sulfide gives at most $\mathrm{pH}$-values rise to two well defined waves. As is found in the polarographic reduction of most of the 2 -substituted acetophenones the height of the second wave is from $\mathrm{pH}$ about 1 to $\mathrm{pH}$ about 6 smaller than the height of the polarographic wave of an equimolar solution of acetophenone. This is believed to be connected with the rate of a reaction between protons and the primarily formed product.

The polarographic data suggest an electrode reaction corresponding to the first wave in which the carbon-oxygen or carbon-sulfur bond is cleaved thus yielding acetophenone and phenol or thiophenol. By controlled potential reduction of phenacyl phenyl ether it was found that acetophenone was formed in good yield both in mineral acid solution and at $\mathrm{pH} 13$.

The polarographic reduction of an aryl alkyl ether is not a frequent polarographic electrode reaction, but has previously been found in the reduction of phenoxyacetamidines ${ }^{10}$. The protection of a phenolic group by transforming it to a benzyl ether followed by a cleavage of the ether bond by hydrogenation is well known; it was attempted to reduce phenyl benzyl ether in buffered media, but no reduction wave was found between 0 and $2.0 \mathrm{~V}$ vs S.C.E. A protection of a phenolic group by a phenacyl group followed by an electrolytic cleavage of the ether bond might be possible, but whether it would present any advantage in comparison with the known method will be investigated. 
The half-wave potential of the first wave of 2 -thiocyanatoacetophenone is independent of $\mathrm{pH}$ at $\mathrm{pH}$-values higher than about 3 , whereas the halfwave potential of the second wave is similar to that of acetophenone in the media employed. The polarographic data thus suggest that acetophenone is formed in the electrode reaction corresponding to the first wave and this was also found by a controlled potential reduction of 2-thiocyanatoacetophenone in an acetate buffer $\mathrm{pH} 5$. The electrode reaction can be formulated as

$$
\begin{aligned}
\mathrm{C}_{6} \mathrm{H}_{6} \mathrm{COCH}_{2} \mathrm{SCN}+2 e^{-} & \longrightarrow \mathrm{C}_{6} \mathrm{H}_{5} \mathrm{COCH}_{2}^{-}+\mathrm{SCN}^{-} \\
+\mathrm{H}^{+} & \rightarrow \mathrm{C}_{6} \mathrm{H}_{5} \mathrm{COCH}_{3}
\end{aligned}
$$

The electrode reaction is thus different from those of aromatic thiocyanates ${ }^{11,12}$, which are reduced to the mercapto derivative and cyanide ion.

The half-wave potential of the first wave of phenacyl nitrate is independent of $\mathrm{pH}$. The following waves are consistent with the assumption that 2 -hydroxyacetophenone and nitrous acid are formed in the electrode reaction which thus would be similar to that of other organic nitrates ${ }^{13}$.

In Table 2 are found polarographic data for 2-acetoxy-4'-chlorobutyrophenone (VIII), 2-thiocyanato-4' -chloro-butyrophenone (IX), and 4'-chlorobutyrophenone (X).

Table 2. Limiting currents in $\mu \mathrm{A}$ and half-wave potentials vs S.C.E. of 2-acetoxy-4'chloro-butyrophenone (VIII), 2-thiocyanato-4'-chlorobutyrophenone (IX), and 4'-chlorobutyrophenone (X). Concentration $10^{-3} \mathrm{M}, 0.008 \%$ gelatin added as maximum sup-

\begin{tabular}{|c|c|c|c|c|c|c|c|c|c|c|c|c|}
\hline \multirow{2}{*}{$\begin{array}{l}\mathrm{pH} \\
\text { Com- } \\
\text { pound }\end{array}$} & \multicolumn{2}{|c|}{1.0} & \multicolumn{2}{|c|}{3.5} & \multicolumn{2}{|r|}{5.3} & \multicolumn{2}{|r|}{7.3} & \multicolumn{2}{|r|}{9.7} & \multicolumn{2}{|r|}{13} \\
\hline & $i_{l}$ & $-E_{\frac{1}{2}}$ & $i_{l}$ & $-E_{\frac{1}{2}}$ & $i_{l}$ & $-E_{\frac{1}{2}}$ & $i_{l}$ & $-E_{\frac{1}{2}}$ & $i_{l}$ & $-E_{\frac{1}{2}}$ & $i_{l}$ & $-E_{\frac{1}{2}}$ \\
\hline VIII & $\begin{array}{l}4.0 \\
1.7\end{array}$ & $\begin{array}{l}0.78 \\
1.06\end{array}$ & 3.8 & 1.03 & 4.1 & 1.22 & 4.1 & 1.34 & $\begin{array}{l}4.0 \\
3.6\end{array}$ & $\begin{array}{l}1.36 \\
1.62\end{array}$ & a & \\
\hline IX & $\begin{array}{l}4.4 \\
1.3\end{array}$ & $\begin{array}{l}0.44 \\
1.04\end{array}$ & 4.3 & 0.44 & 4.3 & 0.44 & $\begin{array}{l}4.1 \\
1.4\end{array}$ & $\begin{array}{l}0.44 \\
1.53\end{array}$ & a & $\begin{array}{l}0.44 \\
1.59\end{array}$ & a & \\
\hline$X$ & 2.5 & 1.03 & 2.5 & 1.21 & 2.5 & 1.33 & 4.1 & 1.53 & 4.3 & 1.60 & 2.6 & 1.75 \\
\hline
\end{tabular}
pressor.

8. The compound is hydrolyzed.

The polarographic reduction of the $4^{\prime}$-chlorobutyrophenones resembles that of the corresponding acetophenones. The height of the second wave is, however, in acid solution much smaller than that of an equimolar solution of the parent ketone and from $\mathrm{pH}$ about 3 the wave is hardly visible. The region in alkaline solution where the second wave is found begins at a higher $\mathrm{pH}$ value than for the corresponding acetophenone derivative. The electrode reactions are similar to those of the corresponding acetophenone derivatives.

In Table 3 are given polarographic data for 2-hydroxyisobutyrophenone (XI), 2-acetoxyisobutyrophenone (XII), and 2-thiocyanatoisobutyrophenone (XIII). 
Table 3. Limiting currents in $\mu \mathrm{A}$ and half-wave potentials vs S.C.E. of 2-hydroxyisobutyrophenone (XI), 2-acetoxyisobutyrophenone (XII), and 2-thiocyanatoisobutyrophenone (XIII). Concentration $10^{-3} \mathrm{M} .0 .008 \%$ gelatin added as maximum suppressor.

\begin{tabular}{|c|c|c|c|c|c|c|c|c|c|c|c|c|c|c|}
\hline $\begin{array}{l}\mathrm{pH} \\
\text { Com- } \\
\text { pound }\end{array}$ & $i_{l}$ & $-E_{\frac{1}{2}}$ & $i_{l}$ & $\begin{array}{l}1.0 \\
-E_{\frac{1}{2}}\end{array}$ & $i_{l}$ & $\begin{array}{l}3.5 \\
-E_{\frac{1}{2}}\end{array}$ & $i_{l}$ & $\begin{array}{l}5.3 \\
-E_{\frac{1}{2}}\end{array}$ & $i_{l}$ & $-E_{\frac{1}{2}}$ & $i_{l}$ & $\begin{array}{l}9.7 \\
-E_{\frac{1}{2}}\end{array}$ & $i_{l}$ & $\begin{array}{l}13 \\
-E_{\frac{1}{2}}\end{array}$ \\
\hline$\underset{\mathrm{XII}}{\mathrm{XI}}$ & $\begin{array}{l}3.7 \\
3.3\end{array}$ & $\begin{array}{l}0.87 \\
0.90\end{array}$ & $\begin{array}{l}3.6 \\
3.2\end{array}$ & $\begin{array}{l}0.94 \\
1.00\end{array}$ & $\begin{array}{l}a \\
a\end{array}$ & & $\begin{array}{l}4.2 \\
3.7\end{array}$ & $\begin{array}{l}1.54 \\
1.50\end{array}$ & $\begin{array}{l}4.2 \\
3.8\end{array}$ & $\begin{array}{l}1.57 \\
1.54\end{array}$ & $\begin{array}{l}4.2 \\
4.3\end{array}$ & $\begin{array}{l}1.63 \\
1.55\end{array}$ & $\begin{array}{l}4.2 \\
\mathrm{~b}\end{array}$ & $\begin{array}{l}1.73 \\
1.57 \\
1.78\end{array}$ \\
\hline XIII & 3.8 & 0.36 & 4.3 & 0.38 & 4.3 & 0.38 & 4.2 & 0.38 & 4.5 & 0.38 & $\mathrm{~b}$ & & b & $\mathrm{b}$ \\
\hline
\end{tabular}

a. Poorly defined wave.

b. The compound is hydrolyzed.

In the polarographic reduction of derivatives of $i$ sobutyrophenone a reduction wave of the isobutyrophenone formed in the first electrode reaction is hardly visible in acid solution and in alkaline solution the wave can only be seen at high $\mathrm{pH}$-values $(\mathrm{pH}>10.5)$. The compounds here investigated are, however, hydrolyzed at high $\mathrm{pH}$-values which makes measurements difficult.

Controlled potential reductions in mineral acid solution at a cathode potential corresponding to the half-wave potential of the compound in the medium employed showed that the electrode reaction of 2-hydroxyisobutyrophenone and 2-thiocyanatoisobutyrophenone was a two-electron reduction to isobutyrophenone. Although it thus is demonstrated that isobutyrophenone is formed in the reduction of 2-thiocyanatoisobutyrophenone no polarographic

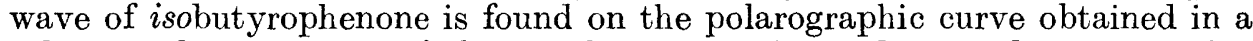
solution of 2-thiocyanatoisobutyrophenone in the medium and concentration here employed.

In the preparative reduction of 2 -hydroxyisobutyrophenone it is not possible to use a cathode potential corresponding to a potential where the polar-

Table 4. Limiting currents in $\mu \mathrm{A}$ and half-wave potentials $v s$ S.C.E. of benzoin (XIV), acetylbenzoin (XV), 2-thiocyanatodeoxybenzoin (XVI), 2-chlorodeoxybenzoin (XVII), and deoxybenzoin (XVIII). Concentration $10^{-3}$ M. $0.008 \%$ gelatin added as maximum suppressor.

\begin{tabular}{|c|c|c|c|c|c|c|c|c|c|c|c|c|c|c|}
\hline $\begin{array}{l}\mathrm{pH} \\
\text { Com- } \\
\text { pound }\end{array}$ & $i_{l}$ & $-E_{\frac{1}{2}}$ & $i_{l}$ & $\begin{array}{l}1.0 \\
-E_{\frac{1}{2}}\end{array}$ & $i_{l}$ & $\begin{array}{l}3.5 \\
-E_{\frac{1}{2}}\end{array}$ & $i_{l}$ & $\begin{array}{l}5.3 \\
-E_{\frac{1}{2}}\end{array}$ & $i_{l}$ & $\begin{array}{l}7.3 \\
-E_{\frac{1}{2}}\end{array}$ & $i_{l}$ & $\begin{array}{l}9.8 \\
-E_{\frac{1}{2}}\end{array}$ & $i_{l}$ & $\begin{array}{l}13 \\
-E_{\frac{1}{2}}\end{array}$ \\
\hline XIV & $\begin{array}{l}4.4 \\
0.9\end{array}$ & $\begin{array}{l}0.79 \\
1.01\end{array}$ & 4.4 & 0.87 & 4.9 & 1.15 & 4.4 & 1.32 & 4.6 & 1.44 & 4.7 & 1.57 & 4.0 & 1.65 \\
\hline XV & $\begin{array}{l}3.8 \\
0.8\end{array}$ & $\begin{array}{l}0.73 \\
1.01\end{array}$ & 3.4 & 0.80 & a & & 4.0 & 1.27 & $\begin{array}{l}3.8 \\
1.0\end{array}$ & $\begin{array}{l}1.34 \\
1.5\end{array}$ & $\begin{array}{l}3.8 \\
3.4\end{array}$ & $\begin{array}{l}1.36 \\
1.58\end{array}$ & $\mathrm{~b}$ & \\
\hline $\begin{array}{l}\text { XVIC } \\
\text { XVI }\end{array}$ & & 0. & 3.7 & 0.2 & 3. & 0.2 & 3. & 0.20 & & 0.20 & b & & b & \\
\hline XVII & $\begin{array}{l}3.8 \\
1.2\end{array}$ & $\begin{array}{l}0.16 \\
1.01\end{array}$ & 3.6 & 0.15 & 3.8 & 0.13 & 3.6 & 0.13 & 3.9 & & $\begin{array}{l}3.8 \\
3.2\end{array}$ & $\begin{array}{l}0.21 \\
1.58\end{array}$ & $\mathrm{~b}$ & \\
\hline CVIII & 2.0 & 0.98 & 1.9 & 1.03 & 2.0 & 1.18 & $2.7^{\mathrm{a}}$ & 1.33 & 3.7 & 1.47 & 4.2 & 1.56 & 2.3 & 1.65 \\
\hline
\end{tabular}

a. Poorly defined wave.

b. The compound is hydrolyzed.

c. $40 \%$ dioxane.

Acta Chem. Scand. 14 (1960) No. 9 
ographic limiting current is reached as the half-wave potential of the isobutyrophenone formed in the reduction is only $0.2 \mathrm{~V}$ more negative than that of 2-hydroxyisobutyrophenone. This can not be predicted from the polarographic curve of 2-hydroxyisobutyrophenone and the polarographic data are thus in such a case not a reliable guide for the reduction.

The polarographic data of the following derivatives of deoxybenzoin are found in Table 4: benzoin (XIV), acetylbenzoin (XV), 2-thiocyanatodeoxybenzoin (XVI), 2-chlorodeoxybenzoin (XVII), and deoxybenzoin (XVIII).

The polarographic behaviour of derivatives of deoxybenzoin resembles that of the above mentioned compounds. Whereas 2-thiocyanatodeoxybenzoin only yields a single wave acetylbenzoin shows a small second wave in strongly acid solution and a second wave with a height corresponding to a two-electron reduction in alkaline solution. The second wave appears in both cases at the potential at which deoxybenzoin is reduced in the same solution. The assumption that the reduction corresponding to the first wave of acetylbenzoin yielded deoxybenzoin was confirmed by a controlled potential reduction of acetylbenzoin from which deoxybenzoin could be isolated in good yield.

Benzoin yields in alkaline solution quantitatively hydrobenzoin ${ }^{\circ}$ but from a reduction in mineral acid solution Pasternak ${ }^{6}$ isolated the highest melting form ( $\alpha$-form) of deoxybenzoinpinacol (1,2-diphenyl-1,2-dibenzyl-ethylene glycol). Wawzonek ${ }^{14}$ has interpreted the occurrence of this reduction product as being due to a reduction of the benzoin to hydrobenzoin followed by an acid catalyzed dehydration to deoxybenzoin which on reduction produced among other compounds the isolated pinacol.

A solution of hydrobenzoin in $\mathbf{N}$ hydrochloric acid solution containing $40 \%$ alcohol was, however, not dehydrated to deoxybenzoin on standing at room temperature for $18 \mathrm{~h}$ as no polarographic wave of deoxybenzoin appeared, and in view of the results from the reduction of acetylbenzoin in mineral acid solution it seems just as plausible that the secondary alcohol group of benzoin is reduced directly to a methylene group and the deoxybenzoin thus formed is reduced further. A polarographic reduction of a secondary alcohol to a methylene group has also been assumed by Wawzonek and Fredrickson ${ }^{15}$ in the reduction of $\alpha$-hydroxy- $p$-methoxy-phenylacetonitrile, and it was shown that $\alpha$-benzoxy-p-methoxy-phenylacetonitrile in good yield formed $p$-methoxyphenylacetonitrile on electrolytic reduction at a mercury cathode.

The reduction of deoxybenzoin is of some interest. It has long been known that two pinacols of deoxybenzoin exist, " $\alpha$ ", m.p. $212^{\circ}$, and " $\beta$ ", m.p. $173^{\circ}$; the existence of these two forms is due to two asymmetric carbon atoms in the pinacols. From a controlled potential reduction of deoxybenzoin in mineral acid solution the pinacol with m.p. $212^{\circ}$ (" $\alpha$ ") precipitated; this is in agreement with Pasternak's results from the reduction of benzoin under similar conditions. Other compounds, probably formed by dehydration and rearrangement of the pinacol, were also formed. In strongly alkaline solution in $60 \%$ dioxane some secondary alcohol was formed but the main product was a mixture of pinacols which consisted mainly of the lower melting isomer; an infrared analysis of the mixture suggested about $80 \%$ " $\beta$-pinacol" and $20 \%$ " $\alpha$ pinacol". In acid solution thus mainly the highest melting and in alkaline solution mainly the lowest melting pinacol is formed. A similar observation 
Table 5. Limiting currents in $\mu \mathrm{A}$ and half-wave potentials vs S.C.E. of phenylbenzoin (XIX), 2-acetoxy-2,2-diphenylacetophenone (XX), 2-methoxy-2,2-diphenylacetophenone (XXI), and 2,2-diphenylacetophenone (XXII). Concentration $10^{-3}$ M. $0.008 \%$ gelatin added as maximum suppressor.

\begin{tabular}{|c|c|c|c|c|c|c|c|c|c|c|c|c|c|c|}
\hline $\begin{array}{l}\mathrm{pH} \\
\text { Com- } \\
\text { pound }\end{array}$ & $i_{l}$ & $-E_{\frac{1}{2}}$ & $i_{l}$ & $\begin{array}{l}1.0 \\
-E_{\frac{1}{2}}\end{array}$ & $i_{l}$ & $-E_{\frac{1}{2}}$ & $i_{l}$ & $-E_{\frac{1}{2}}$ & $i_{l}$ & $-E_{\frac{1}{2}}$ & $i_{l}$ & $\begin{array}{l}9.8 \\
-E_{\frac{1}{2}}\end{array}$ & $i_{l}$ & $\begin{array}{l}13 \\
-E_{\frac{1}{2}}\end{array}$ \\
\hline XIX & 3.7 & 0.88 & 3.4 & 0.95 & $3.2^{\mathrm{a}}$ & 1.23 & 3.2 & 1.35 & 3.4 & 1.45 & 3.6 & 1.56 & $\begin{array}{l}3.2 \\
1.7\end{array}$ & $\begin{array}{l}1.63 \\
1.75\end{array}$ \\
\hline $\mathrm{XX}$ & 2.9 & 0.80 & 2.9 & 0.88 & $\mathrm{a}$ & & 2.9 & 1.37 & 3.1 & 1.38 & 3.1 & 1.39 & $\begin{array}{l}3.2^{\mathrm{b}} \\
2.0\end{array}$ & $\begin{array}{l}1.39 \\
1.73\end{array}$ \\
\hline $\mathrm{XXI}$ & 3.3 & 0.88 & 3.3 & 0.96 & $2.2^{\mathrm{a}}$ & 1.16 & $\mathbf{a}$ & & 3.1 & 1.48 & 3.3 & 1.53 & $\begin{array}{l}3.1 \\
1.7\end{array}$ & $\begin{array}{l}1.55 \\
1.72\end{array}$ \\
\hline XXII & 1.7 & 1.03 & 1.7 & 1.05 & $2.8^{\mathrm{a}}$ & 1.34 & 3.3 & 1.37 & 3.5 & 1.53 & 3.4 & 1.59 & 1.8 & 1.71 \\
\hline
\end{tabular}

a. Poorly defined wave.

b. The compound is hydrolyzed.

has been made by Allen ${ }^{16}$ in the reduction of $p$-dimethylaminoacetophenone which in acid solution was reduced to the higher melting pinacol and in alkaline solution to a lower melting pinacol. The reduction of certain $\alpha, \beta$-unsaturated 3-ketosteroids ${ }^{17}$ also produced a different mixture of pinacols in acid and alkaline solution, and in this connection it is also of interest that the polarographic reduction of $\alpha$-methyldeoxybenzoin in weakly alkaline solution primarily yielded the erythro-alcohol ${ }^{18}$.

In Table 5 are found polarographic data for phenylbenzoin (XIX), 2acetoxy-2,2-diphenylacetophenone (XX), 2-methoxy-2,2-diphenylacetophenone (XXI), and 2,2-diphenylacetophenone (XXII).

The polarographic behaviour of derivatives of diphenylacetophenone resembles that of the derivatives of deoxybenzoin; the second wave of, e.g., 2 -acetoxy-2,2-diphenylacetophenone which is due to the reduction of the diphenylacetophenone formed in the first electrode reaction is, however, only visible at $\mathrm{pH}$-values higher than 11 , whereas the second wave of acetylbenzoin can be seen from about 7.5.

The reduction of 2-methoxy-2,2-diphenylacetophenone is interesting as only few examples of a polarographic reduction of an alkyl arylalkyl ether bond have been reported. A similar reaction has, however, been found in the reduction of $o$-benzoylbenzoic acid pseudoethylester ${ }^{19}$.

Diphenylacetophenone was once believed to exist mainly as triphenylvinyl alcohol; one of the arguments in favour of this formulation was the easy formation of the O-benzoylated derivative, triphenylvinyl benzoate. The polarographic data are consistent with the formulation of 2,2-diphenylacetophenone as a carbonyl compound as the half-wave potentials are close to those of deoxybenzoin, and as it was found that triphenylvinyl benzoate did not yield a polarographic wave in the $\mathrm{pH}$-region in which it is sufficiently stable for a polarographic investigation.

The polarographic behaviour of 2-cyanoacetophenone is quite different from the above mentioned compounds. In acid solution is found one wave with a wave height corresponding to a two-electron reduction, but about

Acta Chem. Scand. 14 (1960) No. 9 
Table 6. Limiting currents in $\mu \mathrm{A}$ and half-wave potentials $v s$ S.C.E. of 2-cyanoacetophenone at different pH-values. Concentration $10^{-8} \mathrm{M} .0 .008 \%$ gelatin added as maximum suppressor.

$\begin{array}{rrrrrrrrr}\mathrm{pH} & i_{l} \mu \mathrm{A} & -E_{\frac{1}{2}} \mathrm{~V} & \mathrm{pH} & i_{l} \mu \mathrm{A} & -E_{\frac{1}{2}} \mathrm{~V} & \mathrm{pH} & i_{l} \mu \mathrm{A} & -E_{\frac{1}{2}} \mathrm{~V} \\ & & & & & & & & \\ 3.57 & 5.30 & 1.15 & 7.63 & 4.55 & 1.35 & 8.55 & 1.60 & 1.41 \\ 5.35 & 5.10 & 1.22 & 7.80 & 4.30 & 1.36 & 9.31 & 1.05 & 1.44 \\ 6.33 & 4.95 & 1.29 & 8.00 & 3.65 & 1.37 & 9.65 & 0.70 & 1.45 \\ 7.31 & 4.85 & 1.32 & 8.29 & 2.40 & 1.38 & 10.50 & 0.25 & 1.51\end{array}$

$\mathrm{pH} 7$ the height of the wave diminishes and the wave disappears about $\mathrm{pH}$ 11 (Table 6).

The reason for this disappearence of the polarographic wave is that the ketone exists in equilibrium with its enol form, and that this enol form in the $\mathrm{pH}$-interval $\mathrm{pH} 7$ to 11 increasingly is found as the enolate-ion according to

$$
\mathrm{C}_{6} \mathrm{H}_{5} \mathrm{COCH}_{2} \mathrm{CN} \rightleftharpoons \mathrm{C}_{8} \mathrm{H}_{5} \mathrm{C}(\mathrm{OH})=\mathrm{CHCN} \rightleftharpoons \mathrm{C}_{6} \mathrm{H}_{5} \mathrm{C}\left(\mathrm{O}^{-}\right)=\mathrm{CHCN}+\mathrm{H}^{+}
$$

The enolate-ion is not reducible in the potential interval $0-2.0 \mathrm{~V}$ vs S.C.E.

This explanation was corroborated by a potentiometric titration of 2 cyanoacetophenone in $40 \%$ alcohol which yielded a normal titration curve, the midpoint being at $\mathrm{pH}$ 7.8. When the height of the polarographic wave is plotted against $\mathrm{pH}$ the $\mathrm{pH}$-value at which the height of the wave has diminished to half of the value in acid solution is 8.2. The curve obtained is not symmetrical as the wave height diminishes too slowly in alkaline solution compared with the decrease about $\mathrm{pH} 7$ to yield a symmetrical curve. This is probably due to a recombination at the electrode surface of the non-reducible enolate anion with a proton to yield the reducible keto form, as the height of the polarographic wave of 2-cyanoacetophenone at $\mathrm{pH} 10$ was not dependent on the height of the mercury reservoir.

The reduction of 2 -bromoacetophenone has been investigated previously ${ }^{1}$; the reduction of the carbon-bromine bond occurs at a very positive potential. When the compound is transformed into its ethylene ketal, 2-(bromomethyl)2-phenyl-1,3-dioxolane, the reduction of the carbon-bromine bond occurs at a much more negative potential. The half-wave potential in a $40 \%$ alcoholic solution containing $4 \%$ tetramethylammonium hydroxide was found to be $-1.78 \mathrm{~V}$ vs S.C.E. This is consistent with the very much lower reactivity of the ketal compared with that of the phenacyl bromide.

\section{DISCUSSION}

When the results from the polarographic investigation and from the controlled potential reductions are compared it is seen that the data obtained at the dropping mercury electrode are not always a reliable guide for the preparative reductions. The observed effects are caused by differences in the duration of the experiments and in the concentrations employed at the dropping mercury electrode and at the macro-scale reductions. 
A species formed as an intermediate in the electrode reaction will at the dropping mercury electrode behave as the final reduction product if it is stable for more than a few seconds; in that case it is able to diffuse from the electrode to the bulk of the solution before it is transformed to the stable reduction product. The concentration of the stable reduction product will remain low and although the compound might be reducible at the electrode its concentration will be too low to influence the recorded polarographic curve.

Differences between the results obtained at the dropping mercury electrode and at the macro electrode are found, e.g., when the relatively stable intermediate is non-reducible and the stable reduction product can be reduced further.

At the macro-electrode the intermediate also is transformed to the stable reduction product in the bulk of the solution but in the course of the reduction a high concentration of this product is built up; if the cathode potential is sufficiently negative the reduction product is reduced further. According to the polarographic data any potential where the diffusion plateau is reached would be equally satisfactory for a preparative reduction but this does not hold true in the case under discussion. The cathode potential must under such circumstances be held more positive than the foot of the polarographic wave of the partially reduced compound and that means that in some cases it is not advisable to employ a cathode potential more negative than the halfwave potential of the compound reduced, if a selective reduction is to succeed.

In this connection it can be recalled that the half-wave potentials of many irreversibly reduced compounds are dependent on the concentration and that the waves at high concentrations often "cover" a greater potential interval than under normal polarographic conditions. The separation of waves obtained in solutions of high concentrations is often less satisfactory than at low concentrations and this makes it advisable always to employ as positive a cathode potential as possible in preparative reductions.

In the present investigation it is found for most of the compounds that in a certain $\mathrm{pH}$-interval either only one wave is detectable, although the product from the first reduction is reducible, or the second wave is smaller than the wave of an equimolar solution of the partially reduced compound. A typical example is 2-thiocyanatoisobutyrophenone which shows only one wave in the $\mathrm{pH}$-interval in which this compound can be investigated; the preparative reduction at controlled cathode potential shows that the product from the electrode reaction corresponding to the observed wave is the reducible isobutyrophenone.

A comparatively stable, non-reducible intermediate is thus likely to be formed during the electrode reaction. The half-wave potential of the wave of 2-thiocyanatoisobutyrophenone is independent of $\mathrm{pH}$ and the reaction can thus be formulated

$$
\begin{aligned}
\mathrm{C}_{6} \mathrm{H}_{5} \mathrm{COC}\left(\mathrm{CH}_{3}\right)_{2} \mathrm{SCN}+2 e^{-} \rightarrow \mathrm{C}_{6} \mathrm{H}_{5} \mathrm{COC}\left(\mathrm{CH}_{3}\right)_{2}^{-}+\mathrm{SCN}^{-} \\
+\mathrm{H}^{+} \rightarrow \mathrm{C}_{6} \mathrm{H}_{5} \mathrm{COCH}\left(\mathrm{CH}_{3}\right)_{2}
\end{aligned}
$$

where the species $\mathrm{C}_{6} \mathrm{H}_{5} \mathrm{COC}\left(\mathrm{CH}_{3}\right)_{2}^{-}$is the non-reducible, relatively stable intermediate. A similar species must be assumed to be formed in the corresponding 
electrode reactions of the compounds investigated, and it is probably stabilized in some way at the electrode.

There seems to be a connection between the strength of the acid from which the substituent is derived and the $\mathrm{pH}$-dependence of the first wave. When the substituent is derived from a strong acid as $\mathrm{HCl}, \mathrm{HBr}, \mathrm{HSCN}$, or $\mathrm{HNO}_{3}$ the halfwave potential of the first wave is independent of $\mathrm{pH}$ above $\mathrm{pH} 2-3$; when the substituent, however, is derived from a weak acid as $\mathrm{HF}^{3}, \mathrm{CH}_{3} \mathrm{COOH}, \mathrm{C}_{6} \mathrm{H}_{5} \mathrm{OH}$, $\mathrm{C}_{6} \mathrm{H}_{5} \mathrm{SH}$, or $\mathrm{CH}_{3} \mathrm{OH}$ the half-wave potential is in acid solution dependent on $\mathrm{pH}$. Considerations as those used by Elving and Leone to explain the $\mathrm{pH}$-dependence of the reduction of 2-fluoroacetophenone may be applied in those cases.

It is of interest to compare for the same derivative of different ketones the $\mathrm{pH}$-intervals in which only one wave is observed. It is found that the interval grows in the order $\mathrm{C}_{6} \mathrm{H}_{5} \mathrm{COCH}_{2} \mathrm{X}<\mathrm{ClC}_{6} \mathrm{H}_{4} \mathrm{COCH}\left(\mathrm{C}_{2} \mathrm{H}_{5}\right) \mathrm{X}<\mathrm{C}_{6} \mathrm{H}_{5} \mathrm{COCH}\left(\mathrm{C}_{6} \mathrm{H}_{5}\right) \mathrm{X}$ $<\mathrm{C}_{6} \mathrm{H}_{5} \mathrm{COC}\left(\mathrm{CH}_{3}\right)_{2} \mathrm{X} \leqq \mathrm{C}_{6} \mathrm{H}_{5} \mathrm{CO}\left(\mathrm{C}_{6} \mathrm{H}_{5}\right)_{2} \mathrm{X}$. This sequence is understandable in view of the reduction route indicated above. The postulated primarily formed carbanion is stabilized by substitution by alkyl or aryl at the carbon atom at which the reduction occurs, and the carbanion thus reacts more slowly with protons to form the reduction product, the ketone. Besides stabilizing the carbanion the substituents may produce a shielding effect which lowers the rate of the reaction with protons.

In the acid region the second wave is greater at the lowest $\mathrm{pH}$-values which is understandable if the rate of a reaction between a carbanion and a proton determines the height of the wave. In the alkaline region the formation of the reducible ketone is most rapid at high $\mathrm{pH}$-values, as if the hydroxyl ions catalyzed the reaction between the carbanion and a water molecule to form the ketone and a hydroxyl ion. This is also found in the reduction of benzil which in most buffers yields only a single wave, although a preparative reduction at controlled potential has shown ${ }^{6}$ that the reducible benzoin is formed. In $0.1 \mathrm{~N}$ sodium hydroxide, however, a wave due to the reduction of the benzoin formed in the first electrode reaction is visible which indicates that the nonreducible intermediate is transformed to benzoin most rapidly in strongly alkaline solution.

\section{EXPERIMENTAL}

The polarograph was a recording polarograph Radiometer Type PO 3 a. The capillary delivered $2.27 \mathrm{mg}$ of mercury at a corrected mercury column height of $48.5 \mathrm{~cm}$. The drop time 3.90 sec. $\left(\mathrm{H}_{2} \mathrm{O}\right.$, open circuit). The capillary constant, $m^{2} / \mathrm{s} t^{1} / \mathrm{s}=2.13 \mathrm{mg} / \mathrm{s} \mathrm{sec}^{-\frac{1}{2}}$.

The apparatus used for the controlled potential reductions was an electromechanical potentiostat of the Lingane-Jones type. The buffer solutions employed were from $\mathrm{pH} 2.5$ to 8 a sodium phosphate-citric acid buffer and from $\mathrm{pH} 8$ to 11 a sodium borate buffer. The medium generally used was $40 \%$ aqueous alcohol containing $1 \mathrm{M}$ potassium chloride and $0.008 \%$ gelatin. In a few cases the alcohol was replaced by peroxide-free dioxane.

The following compounds were prepared according to Organic Syntheses: 2-Bromoacetophenone, desylchloride, deoxybenzoin, benzoin, and acetylbenzoin. By reaction between a bromoketone and an alkali metal salt in alcohol or acetonitrile were prepared: 2-Acetoxyacetophenone, m.p. $48.5^{\circ}-49.5^{\circ}, 2$-acetoxy-4'-chlorobutyrophenone, m.p. $73.5^{\circ}-74^{\circ}, 2$-acetoxyisobutyrophenone, m.p. $61^{\circ}-61.5^{\circ}, 2$-thiocyanatoacetophenone, m.p. $72.5^{\circ}-73.5^{\circ}, 2$-thiocyanato $4^{\prime}$-chloro-butyrophenone, m.p. $67^{\circ}-67.5^{\circ}$. (Found: C 55.05; $\mathrm{H}$ 4.36; $\mathrm{N} 6.01 ; \mathrm{S}$ 13.60. Calc. for $\mathrm{C}_{11} \mathrm{H}_{10}$ ClNOS: $\mathrm{C} 55.10 ; \mathrm{H} 4.20 ; \mathrm{N} 5.85 ; \mathrm{S} 13.37$ ). 2Thiocyanatoisobutyrophenone, m.p. $20^{\circ}-22^{\circ}$. (Found: C 64.31; H 5.31; N 6.60; S 15.56 . 
Calc. for $\mathrm{C}_{11} \mathrm{H}_{11} \mathrm{NOS}$ : $\mathrm{C}$ 64.36; $\mathrm{H}$ 5.40; $\mathrm{N}$ 6.83; $\mathrm{S}$ 15.63). 2-Thiocyanatodeoxybenzoin, m.p. 112.5 $-113^{\circ}$. (Found: $\mathrm{C} 71.06 ; \mathrm{H} 4.14 ; \mathrm{N} 5.46$; $\mathrm{S}$ 12.71. Calc. for $\mathrm{C}_{16} \mathrm{H}_{11} \mathrm{NOS}$ : C 71.12; H 4.38; N 5.53; S 12.66). Phenacyl phenyl ether, m.p. $73^{\circ}-73.5^{\circ}$, phenacyl phenyl sulfide, m.p. $53^{\circ}-53.5^{\circ}, 2$-cyanoacetophenone, m.p. $80.5^{\circ}-81^{\circ}$, phenacyl nitrate, m.p. 53.5 $-54^{\circ}\left(4^{\circ}-5^{\circ}{ }^{20}\right)$. (Found: C 53.06; H 3.98; $\mathrm{N}$ 5.6-7.3. Calc. for $\mathrm{C}_{8} \mathrm{H}_{7} \mathrm{NO}_{4}$ : C 53.04; H 3.89; $\mathrm{N} \mathrm{7.72).} \mathrm{Although} \mathrm{the} \mathrm{nitrogen} \mathrm{determinations} \mathrm{were} \mathrm{low} \mathrm{and} \mathrm{variable}$ the compound isolated from the reaction between phenacyl bromide and silver nitrate in acetonitrile is believed to be phenacyl nitrate. The infrared spectrum of the compound contains strong bands at $1640 \mathrm{~cm}^{-1}$ and $1283 \mathrm{~cm}^{-1}$; covalent nitrates generally absorb in the region $1650-1600 \mathrm{~cm}^{-1}$ and $1300-1250 \mathrm{~cm}^{-1}$.

2-Bromo-2,2-diphenylacetophenone, 2-methoxy-2,2-diphenylacetophenone, and 2hydroxy-2,2-diphenylacetophenone were made according to Stevens and DeYoung ${ }^{21}$, and 2-(bromomethyl)-2-phenyl-1,3-dioxolane according to Kuhn ${ }^{22}$.

Reduction of 2-acetoxyacetophenone: $1.00 \mathrm{~g}$ of 2-acetoxyacetophenone was reduced in $55 \%$ alcoholic $0.1 \mathrm{~N}$ hydrochloric acid at a cathode potential of $-0.9 \mathrm{~V} v s$ S.C.E. The reduction consumed 2.1 electrons per molecule. The odour of the reduction mixture suggested the presence of acetophenone, which was confirmed by polarographic analysis. To the solution were added $2.5 \mathrm{~g}$ of 2,4 -dinitrophenylhydrazine; the precipitate was filtered off and recrystallized from amyl acetate, $1.05 \mathrm{~g}, \mathrm{~m} . \mathrm{p} .246^{\circ}-248^{\circ}$. It was identified as the 2,4-dinitrophenylhydrazone of acetophenone.

2-Hydroxyacetophenone was reduced in $50 \%$ alcoholic $\mathrm{N}$ hydrochloric acid as described above, $n=2.0$. The product was isolated as described above; $1.55 \mathrm{~g}$ of acetophenon $\Theta$ 2,4-dinitrophenylhydrazone.

In a similar manner 2-phenoxyacetophenone was reduced at $-0.85 \mathrm{~V} v s$ S.C.E.; $n=2.0$. Isolated were $1.1 \mathrm{~g}$ of 2,4-dinitrophenylhydrazone of acetophenone.

2-Phenoxyacetophenone was also reduced in $50 \%$ alcoholic $0.1 \mathrm{~N}$ sodium hydroxide at $-1.5 \mathrm{~V}$ vs S.C.E., and in this case, too, the only isolated compound was the 2,4-dinitrophenylhydrazone of acetophenone $(0.65 \mathrm{~g})$.

2-Thiocyanatoacetophenone $(1.00 \mathrm{~g})$ was reduced in an acetate buffer, $\mathrm{pH} 5$, containing $50 \%$ alcohol at $-0.85 \mathrm{~V} v s$ S.C.E., $n=2.0$. From the reduction were isolated acetophenone as its 2,4-dinitrophenylhydrazone $(1.5 \mathrm{~g})$.

Reduction of 2-hydroxyisobutyrophenone: $1.00 \mathrm{~g}$ of 2-hydroxyisobutyrophenone was reduced in $50 \%$ alcoholic $\mathrm{N}$ hydrochloric acid at $-0.85 \mathrm{~V}$ vs S.C.E., $n=2$. On the polarograms from the reaction medium a high wave followed by a very small one were visible at the beginning of the reduction; the first wave disappeared gradually whereas the second wave grew. After completion of the reduction 2,4-dinitrophenylhydrazine was added and the precipitate recrystallized from $n$-butanol, $1.65 \mathrm{~g}, \mathrm{~m} . \mathrm{p} .161^{\circ}-162.5^{\circ}$. It was identified as the 2,4-dinitrophenylhydrazone of isobutyrophenone by the mixed m.p. $160^{\circ}-162^{\circ}$ with an authentic sample of isobutyrophenone 2,4-dinitrophenylhydrazone.

In a similar manner 2-thiocyanatoisobutyrophenone was reduced at $-0.65 \mathrm{~V}$ vs S.C.E. in $50 \%$ alcoholic $\mathrm{N}$ hydrochloric acid; $n=2.0$. From the reduction mixture isobutyrophenone was isolated as its 2,4-dinitrophenylhydrazone $(1.50 \mathrm{~g})$ as described above.

Acetylbenzoin was reduced $(1.00 \mathrm{~g})$ in $\mathrm{N}$ hydrochloric acid containing $50 \%$ dioxane; $n=2$. The reduction mixture was diluted with water and extracted with ether which was dried and evaporated. The residue, $0.83 \mathrm{~g}, \mathrm{~m} . \mathrm{p} .45^{\circ}-50^{\circ}$, was recrystallized from $4 \mathrm{ml}$ methanol. Isolated were $285 \mathrm{mg}$ deoxybenzoin, m.p. $60^{\circ}$, and from the mother liquor $430 \mathrm{mg}$ of deoxybenzoin 2,4 -dinitrophenylhydrazone, m.p. $201^{\circ}-203^{\circ}$.

\section{REFERENCES}

1. Pasternak, R. and von Halban, H. Helv. Chim. Acta 29 (1946) 190.

2. Adkins, H. and Cox, F. W. J. Am. Chem. Soc. 60 (1938) 1151.

3. Elving, P. J. and Leone, J. T. J. Am. Chem. Soc. 79 (1957) 1546.

4. Zuman, P. and Horak, V. 2nd International Congress of Polarography, Cambridge 1959.

5. Fedoronko, M. Chem. zvesti 12 (1958) 17; Chem. Abstr. 52 (1958) 10768.

6. Pasternak, R. Helv. Chim. Acta 31 (1948) 753.

7. Santavy, F. Collection Czechoslov. Chem. Communs. 14 (1949) 145.

Acta Chem. Scand. 14 (1960) No. 9 
8. Kabasakalian, P. and MeGlotten, J. Anal. Chem. 31 (1959) 1091.

9. Zuman, P., Chodkowski, J., Potesilova, H. and Santavy, F. Nature 182 (1958) 1535.

10. Kane, P. O. Z. anal. Chem. 173 (1960) 50.

11. Schwabe, K. and Voigt, J. Z. Elektrochem. 56 (1952) 44.

12. Lanza, P., Griggio, L. and Semerano, G. Ricerca sci. 26 (1956) S 230.

13. Kaufman, F., Cook, H. J. and Davis, S. M. Anal. Chem. 24 (1952) 971.

14. Kolthoff, I. M. and Lingane, J. J. Polarography, 2nd Ed., Interscience Publishers, New York, London 1952, p. 694.

15. Wawzonek, S. and Fredrickson, J. D. J. Electrochem. Soc. 106 (1959) 325.

16. Allen, M. J. J. Chem. Soc. 19511598.

17. Lund, H. Acta Chem. Scand. 11 (1957) 283.

18. Mandell, L., Powers, R. M. and Day, R. A. J. Am. Chem. Soc. 80 (1958) 5284.

19. Lund, H. Acta Chem. Scand. 14 (1960) 359.

20. Emmons, W. D. and Freeman, J. P. J. Am. Chem. Soc. 77 (1955) 4415.

21. Stevens, C. L. and DeYoung, J. J. J. Am. Chem. Soc. 76 (1954) 718.

22. Kuhn, M. J. prakt. Chem. 156 (1940) 103.

Received June 4, 1960. 